\title{
Leadership skills, stakeholder management and execution of fibre-optic infrastructure: intervening influence of government policy
}

DOI 10.2478/otmcj-2020-0014

Received December 27, 2019; accepted March 19, 2020

Abstract: Communication technology has drastically evolved in the last 10 years across the globe. With increased demand for data and voice traffic, fibre-optic network is preferred to transmit high-speed broadband. Nonetheless, fibre-optic infrastructure involves huge construction challenges and continues to fail because of ineffective leadership, stakeholder management and government policies. The main purpose of this study was to investigate how government policy intervenes on the joint influence of leadership skills and stakeholder management on execution of fibre-optic infrastructure in Nairobi County, Kenya. This study adopted the pragmatism paradigm approach, with a cross-sectional survey design. Census was used to select 187 respondents from a target population of 187 functional staff in fibre-optic infrastructure departments. A questionnaire was used to collect quantitative data while an interview guide was used to collect qualitative data. Statistical analysis techniques were used to analyse the data. It was demonstrated that government policy has a significant intervening influence on the joint influence of leadership skills and stakeholder management on execution of fibre-optic infrastructure. Therefore, governments should come up with policies to guide and regulate execution of fibre-optic infrastructure, review building code to allow for fibre-optic services in new buildings, develop right of way conduits and establish a centrally coordinated authority to facilitate time-bound issuance of permits and related services. It was suggested that similar studies should be carried out in other countries and target vendors and contractors engaged in supply of equipment and construction of fibre-optic infrastructure.

\footnotetext{
*Corresponding author: James Akhwaba, University of Nairobi Jomo Kenyatta Memorial Library, Nairobi, Kenya.

E-mail: saulokonya@yahoo.com
}

Keywords: leadership skills, stakeholder management, government policy, execution, fibre-optic infrastructure, mobile telecommunication, internet service provision

\section{Introduction}

Project planning and management focuses on organisation as well as management of complex arrays of activities that deliver a project such as fibre-optic infrastructure (Morris 1994). In projects, things often do not happen according to plans and this can cause conflict among stakeholders. Therefore, there is a real need for project leaders who can manage tasks and people (Qing and Dekker 2014). Leadership skills help project managers empower teams and other stakeholders, list down all stakeholders, assess their interest in the project, use influence and communication skills to convey and sell project vision to stakeholders, shape expectations and affirm successful execution of projects (Qing and Dekker 2014).

Leadership skills are therefore vital in defining project vision, scope and managing stakeholders throughout the project's life cycle. In fibre-optic infrastructure, governments, operators, constructors and equipment vendors are the main stakeholders who take major responsibilities (Huawei 2016). Hence, the need to strike a balance to see that fibre-optic infrastructure has right response from stakeholders is important to policymakers. Gillwald et al. (2012) postulated that a policy is a set of basic principles, directed towards a long-term objective or to a problem. Such principles by governments are often tied to the laws governing the country and it is meant to give proactive approach in decision-making (Gillwald et al. 2012). Policies assist to save time, avoid mistakes relating to management, improve steadiness in decision-making and focus on decisions that are made towards business objectives. Although formalisation of policies is done by the governments, private sector may give their views on policy which may affect its results. The government therefore provides 
an environment that is conducive for the process of an information and communication technology (ICT) policy development (Republic of Kenya 2016).

Telecommunication and internet service enterprise has drastically evolved in the last 10 years across the globe. Consequently, customers and business enterprises with smart devices consume huge amount of data and increased voice traffic (Ernst and Young 2015). One of the innovations to beat this new development in telecommunication industry is the emergence of fibre-optic telecommunication network. Optical fibre is the globally preferred technology to supply high-speed broadband to end users (Beardsley et al. 2011), and therefore it is a major building block in telecommunication infrastructure (Ezeh et al. 2013; Massa 2013). Torlak (2013) defined optic fibre as flexible, long, transparent thin strands of glass or plastic about a diameter slightly thinner than human hair. Light signal from fibre-optic cables does not cause interference among other fibre-optic cables in the same channel. Optical fibre is therefore suitable for transmission of digital information that is useful in computer and telecommunication networks (Sankara 2014; Massa 2013).

Nevertheless, fibre-optic network involves construction challenges far beyond those associated with traditional construction projects on a contained and easily controlled site (Crocker 2012). Crocker (2012) also noted that fibre-optic construction involves huge risks from weather as well as in safety and land access. Similarly, Deloitte (2016) noted that lack of uniformity in policy, logistics in procurement, staff mobilisation, equipment and materials transport to sites also result in significant challenges in fibre-optic network. Furthermore, fibre construction happens in communities for short periods, and therefore a complex programme of proactive community engagement with operators, constructors, government agencies, environment groups and property owners is an essential part in meeting schedules and budget (Huawei 2016).

In the United States, Kraus and Quiroga (2016) showed in their study that utilisation of utility strips, also known as utility corridors, plays a major role in preventing repeated digging that interferes with other underground infrastructure. CTC Technology and Energy (2017) asserted that though fibre and conduit materials are relatively inexpensive, dig once construction is still costly. It was also found out that more regulations should be put in place to check on how fibre-optic infrastructure is implemented (Kraus and Quiroga 2016). Lampland and Mitchell (2014) showed in their study that ambiguity around the process to obtain permissions, delays caused due to administrative paperwork and complex processes highlighted by authorities at the local government level negatively affect project success.

In Russia, Karakozova and Prokhorova (2016) noted that companies should adopt international standards in the implementation of fibre-optic infrastructure. In Scandinavian countries, Strand (2015) showed that dig once policies minimise the long-term cost of constructing communication facilities by capitalising on economies of scale. The application of dig once policy is by grouping of fibre and conduit construction with utility construction and other activities that interfere in the public right of way. It involves construction of spare conduit capacity where multiple service providers or entities may require infrastructure in future (Strand 2015).

In India, Deloitte (2016) showed that while project execution depends on various government policies such as building code, ICT policies and environmental policies, government policies too influence leadership and stakeholder management in different organisations. Setting standards enables fibre-optic infrastructure process to become sustainable from an environmental perspective. The life and quality of fibre-optic cable network is critically dependent on the physical network design and installation practices. Therefore, according to Huawei (2016), global standards and scalable network design optimise network sizing and installation of the network.

Jere and Biru (2015) studied internet development and governance in Africa. The findings of the study showed that destruction of network was as a result of regular cause of fibre cuts from construction firms that do not adhere to procedures and municipality by-laws because of non-unified backbone infrastructure (Jere and Biru 2015). Ameh and Ogunyemi (2015) revealed in their study in Nigeria that project scope planning, definition and verification must take into consideration the regulatory policies in place for smooth execution of fibre-optic infrastructure. In addition, there was no uniform right of way policy for fibre-optic infrastructure and other related infrastructure. While a uniform right of way is effective in preventing digging more than once, Kraus and Quiroga (2016) showed in their study that uniform right of way was missing in most countries including Kenya.

The reports of Republic of Kenya (2016) indicated that a government has a huge influence on execution of any project since it provides policies for improvement in project productivity, management and associated benefits to different stakeholders. Infrastructure-related policy that aimed to ensure affordable and widespread access to ICT services is required implying that there is inadequacy in the infrastructure-related policy to guide fibre-optic 
infrastructure (Republic of Kenya 2016). Collaboration on International ICT Policy in Eastern and Southern Africa [CIPESA] (2016) noted that ICT policy involving ICT infrastructure in Kenya needs revision. Similarly, Communication Authority of Kenya (2017) indicated that keeping in mind the need for advancing ubiquitous broadband, the Kenya National Telecom Policy needs revision with deeper focus on strategic direction, increased clarity around policy actions for implementation and a robust governance framework. Moenga and Moronge (2016) showed in their study that stakeholder participation through wellplanned project scope under leadership of a competent project manager in fibre-optic infrastructure with strict adherence to government policies helps to realise success in execution of fibre-optic projects. The study recommended that organisations should adopt a strategic plan for effective utilisation of fibre-optic infrastructure and that national ICT policy should articulate a strategic utilisation roadmap for the deployed fibre-optic infrastructure (Moenga and Moronge 2016).

Fibre-optic infrastructure involves a complex stakeholder management framework and policies across a wide range of groups requiring constant engagement to provide management oversight through formal reporting, audit and assurance mechanism to ensure successful execution (Crocker 2012). Despite advanced project management methodologies, many projects including fibre-optic infrastructure in Kenya and indeed across the world continue to fail and deliver beyond projected timelines, budget and scope for several reasons, including inadequate government policies. The need for adequate government policies is therefore acceptable among professionals in project planning and management.

The studies on government policies notwithstanding the intervening influence of government policy on the joint influence of leadership skills and stakeholder management on execution of fibre-optic infrastructure are not clear. The issue is that projects remain unsuccessful because of inadequate government policies. However, empirical evidence suggested that government policy may contribute to overcoming challenges faced by projects including fibre-optic infrastructure. Even with previous studies focusing on ICT infrastructure and construction projects in general, none has focused on the intervening influence of government policy on joint influence of leadership skills and stakeholder management on execution of fibre-optic infrastructure and interaction among the variables. This study was therefore carried out to fill this knowledge gap with reference to the joint influence of leadership skills and stakeholder management on execution of fibre-optic infrastructure.
The objective of this study was to determine how government policy intervenes on the joint influence of leadership skills and stakeholder management on execution of fibre-optic infrastructure. This study tested the hypothesis that there is no significant intervening influence of government policy on the joint influence of leadership skills and stakeholder management on execution of fibre-optic infrastructure. Government policy was the intervening variable. Leadership skills and stakeholder management were independent variables while execution of fibre-optic infrastructure was the dependent variable. The target population comprised of functional members of staff in fibre-optic infrastructure departments of mobile telecommunication and internet service companies that own and deploy fibre-optic infrastructure with their headquarters in Nairobi County, Kenya. It is expected that findings of this study will be valuable to academicians, policymakers and other researchers as they add to the existing body of knowledge in project management, telecommunication industry and fibre-optic infrastructure and construction industry. The study findings would also form a guideline for project planning and implementation which helps organisations to get on track and deliver more successful construction projects including fibre-optic infrastructure.

\section{Methodology}

This study was anchored on the conceptual framework that execution of fibre-optic infrastructure may be predicted by joint influence of leadership skills and stakeholder management, mediated by government policy. 'Leadership skills' is the independent variable and has indicators, namely, visionary capacity, team building, communication, planning, delegation, problem solving and decision-making, coaching and training. Stakeholder management is also an independent variable with the indicators, namely, stakeholder list with areas of interest, stakeholder analysis, dynamics of stakeholders in the project's life cycle, stakeholder's reaction to project decisions and stakeholder's engagement through the project's life cycle. ICT, dig once, right of way, utility corridor, regulations and universal standards are indicators of the government policy which is the intervening variable. In this study, execution of fibre-optic infrastructure is the dependent variable with indicators, namely, timeline, cost savings, quality standards, stakeholder satisfaction, learnt lesson reports, project benefits, handover documents and project team commitment.

This study adopted the pragmatism paradigm approach, with a cross-sectional survey design. Target 
population was 187 comprised of functional members of staff in fibre-optic infrastructure departments of two mobile telecommunication organisations, four internet service providers and two policymaking and regularity authorities. The functional members of staff comprised of construction professionals, namely, engineers, project managers and supervisors, who are members of relevant professional bodies. The functional members of staff were distributed as follows: Telkom Ltd -25 , Safaricom PLC 45, Liquid Telecom - 30, Jamii Telecom - 25, Access Kenya - 30, Wananchi Group - 30, ICT Authority - 1 and Communication Authority - 1. The sample size of the study comprised the entire target population of 187 respondents. The researcher used a raffle containing eight names of the target organisations to choose organisation from where survey started among the eight organisations. The researcher used first raffle to start survey.

This study used qualitative and quantitative data with questionnaire, interview schedule and document review guide as data collection instruments. The questionnaire had visual analogue scale with a range of $0-10$ and 5-point grouped Likert scale. On the Likert scale, 5 represents strongly agree, 4 represents agree, 3 represents neutral, 2 represents disagree and 1 represents strongly disagree. The interpretation of arithmetic mean in Likert questions shows that strongly disagree is between 1 and 1.5, disagree is between 1.5 and 2.5, neutral is between 2.5 and 3.5, agree is between 3.5 and 4.5 and strongly agree is between 4.5 and 5.0 (Vonglao 2017). The Likert scale data was used for descriptive analysis. The visual analogue scale measured the opinion ratings on an interval scale (Dexter and Chestnut 1995), and therefore data from visual analogue scale was used to carry out inferential statistical analysis.

Prior to data collection, preliminary testing of research instruments was done through content-related method and Cronbach's alpha technique to verify validity and reliability, respectively. Census was used to select 187 respondents from a target population of 187 functional staff in mobile telecommunication and internet service companies through purposive sampling. Therefore, the sample size of the study was 179 functional staff in fibre-optic infrastructure departments of mobile telecommunication and internet service companies in Nairobi County, Kenya and 8 key informants. Out of 179 questionnaires that were distributed during this study, 172 were duly filled and returned to the researcher. In addition, six interviews were carried out. Therefore, the response rate was $95.18 \%$. According to Bryman (2012), a $50 \%$ response rate is adequate for analysis, making conclusions and inferences about a population. This implied that the response rate (95.18\%) was adequate for analysis, making conclusions and reporting.

On the visual analogue scale with a range of $0-10$, the respondents were requested to rate the performance of their companies in execution of fibre-optic infrastructure, the extent to which leadership skills had been applied in their companies in steering company projects towards their intended goals, the performance of their companies in stakeholder management and the extent to which government policy is supportive to execution of fibre-optic infrastructure. The key informants were asked to indicate whether key stakeholders are involved in fibre-optic infrastructure policy formulation, challenges experienced, possible solutions to the challenges and if policies were adequate.

Data analysis proceeded in three steps: data preparation, data analysis and reporting. Mixed methods of data analysis were adopted in this study incorporating descriptive, inferential and content analysis. The instruments were assembled, sorted and prepared for analysis after completion of data collection exercise, and quantitative data were coded and analysed using descriptive and inferential statistics. This study used summary statistics to analyse descriptive data. Inferential statistical analysis was performed using path analysis. Prior to the main data analysis, statistical investigation involving tests for statistical assumptions of linearity, normality, homoscedasticity, multicollinearity and autocorrelation was performed. Qualitative data were analysed using content analysis.

\section{Research data}

This section summarises quantitative research data.

\subsection{Performance of the companies in execution of fibre-optic infrastructure}

Table 1 summarises the number of respondents who gave different ratings to performance of companies in execution of fibre-optic infrastructure.

\subsection{Extent to which leadership skills are applied in steering fibre-optic infrastructure}

Table 2 summarises the number of respondents who gave different ratings on visual analogue scale on the extent to which leadership skills are applied in steering execution of fibre-optic infrastructure towards their intended goals. 


\subsection{Performance of the companies in stakeholder management}

Table 3 summarises the number of respondents who gave different ratings on visual analogue scale on the performance of the companies in stakeholder management.

\subsection{Government policy and execution of fibre-optic infrastructure}

Table 4 summarises the responses on government policy on a Likert scale.

Tab. 1: Performance of companies in execution of fibre-optic infrastructure

\begin{tabular}{lcc}
\hline Score & Frequency & Percentage \\
\hline 2.00 & 2 & 1.2 \\
3.00 & 4 & 2.3 \\
4.00 & 6 & 3.5 \\
5.00 & 10 & 5.8 \\
6.00 & 24 & 14.0 \\
7.00 & 30 & 17.4 \\
8.00 & 38 & 22.1 \\
9.00 & 38 & 22.1 \\
10.00 & 20 & 11.6 \\
Total & 172 & 100.0 \\
\hline
\end{tabular}

Tab. 2: Extent to which leaderships skills are applied in steering fibre-optic infrastructure

\begin{tabular}{lcc}
\hline Score & Frequency & Percentage \\
\hline 2.00 & 4 & 2.3 \\
3.00 & 8 & 4.7 \\
4.00 & 4 & 2.3 \\
5.00 & 14 & 8.1 \\
6.00 & 18 & 10.5 \\
7.00 & 34 & 19.8 \\
8.00 & 48 & 27.9 \\
9.00 & 22 & 12.8 \\
10.00 & 20 & 11.6 \\
Total & 172 & 100.0 \\
\hline
\end{tabular}

Tab. 3: Performance of companies in stakeholder management

\begin{tabular}{lcc}
\hline Score & Frequency & Percentage \\
\hline 2.00 & 6 & 3.5 \\
3.00 & 4 & 2.3 \\
4.00 & 4 & 2.3 \\
5.00 & 28 & 16.3 \\
6.00 & 30 & 17.4 \\
7.00 & 12 & 7.0 \\
8.00 & 38 & 22.1 \\
9.00 & 30 & 17.4 \\
10.00 & 20 & 11.6 \\
Total & 172 & 100.0 \\
\hline
\end{tabular}

Tab. 4: Descriptive analysis of government policy from Likert scale data

\begin{tabular}{|c|c|c|c|c|c|c|c|}
\hline Statements & 1 & 2 & 3 & 4 & 5 & Mean & Standard deviation \\
\hline $\begin{array}{l}\text { Government of Kenya has implemented policy on fibre-optic } \\
\text { infrastructure }\end{array}$ & 8.1 & 15.1 & 27.9 & 31.4 & 17.4 & 3.348 & 1.172 \\
\hline $\begin{array}{l}\text { The government implements a dig once policy in conjunction } \\
\text { with laying new roads and widening some }\end{array}$ & 16.3 & 19.8 & 30.2 & 27.9 & 5.8 & 2.872 & 1.162 \\
\hline $\begin{array}{l}\text { There is a uniform right of way policy for fibre-optic and other } \\
\text { infrastructures }\end{array}$ & 11.6 & 26.7 & 26.7 & 24.4 & 10.5 & 2.953 & 1.183 \\
\hline $\begin{array}{l}\text { Significant delays in execution of fibre-optic infrastructure as a } \\
\text { result of delays in obtaining permits }\end{array}$ & 2.3 & 5.8 & 12.8 & 24.4 & 54.7 & 4.232 & 1.033 \\
\hline $\begin{array}{l}\text { Lack of coordination among multiple authorities in issuance of } \\
\text { permits is a reason for significant delays }\end{array}$ & 2.3 & 5.8 & 12.8 & 24.4 & 54.7 & 4.232 & 1.033 \\
\hline $\begin{array}{l}\text { Introduction of utility corridors will prevent repeated digging } \\
\text { which interfere with other underground infrastructure }\end{array}$ & 2.3 & 1.2 & 7.0 & 30.2 & 59.3 & 4.430 & 0.858 \\
\hline $\begin{array}{l}\text { Regulations by the government on fibre-optic infrastructure are } \\
\text { not fair and should be revised }\end{array}$ & 5.8 & 4.7 & 36.0 & 22.1 & 31.4 & 3.686 & 1.136 \\
\hline $\begin{array}{l}\text { More regulations should be put in place to check on how } \\
\text { fibre-optic infrastructure is implemented }\end{array}$ & 1.2 & 4.7 & 7.0 & 38.4 & 48.8 & 4.290 & 0.876 \\
\hline $\begin{array}{l}\text { Global standards are adopted and customised in implementa- } \\
\text { tion of fibre-optic infrastructure }\end{array}$ & 3.5 & 15.1 & 25.6 & 30.2 & 25.6 & 3.593 & 1.127 \\
\hline $\begin{array}{l}\text { Building code should be revised to allow for fibre-optic services } \\
\text { in new buildings }\end{array}$ & 0.0 & 3.5 & 4.7 & 29.1 & 62.8 & 4.511 & 0.745 \\
\hline Average & & & & & & 3.8147 & 1.0325 \\
\hline
\end{tabular}


Tab. 5: Descriptive analysis of government policy from visual analogue scale data

\begin{tabular}{lcc}
\hline Score & Frequency & Percentage \\
\hline 2.00 & 2 & 1.2 \\
3.00 & 10 & 5.8 \\
4.00 & 4 & 2.3 \\
5.00 & 24 & 14.0 \\
6.00 & 20 & 11.6 \\
7.00 & 36 & 20.9 \\
8.00 & 44 & 25.6 \\
9.00 & 26 & 15.1 \\
10.00 & 6 & 3.5 \\
Total & 172 & 100.0 \\
\hline
\end{tabular}

\subsection{Extent to which government policy is supportive to execution of fibre-optic infrastructure}

Table 5 summarises the number of respondents who gave different ratings on visual analogue scale on the extent to which government policy is supportive to execution of fibre-optic infrastructure.

\section{Findings}

The objective of this study was to determine how government policy intervenes on the joint influence of leadership skills and stakeholder management on execution of fibre-optic infrastructure. From empirical and conceptual review, the indicators of government policy in relation to execution of fibre-optic infrastructure in this study were as follows: ICT, dig once, right of way, utility corridor, regulations and universal standards.

\subsection{Descriptive analysis of government policy from Likert scale data}

The participants were requested to indicate their level of agreement with various statements on the role of government policy in fibre-optic infrastructure. The findings are presented in Table 4. As shown in the table, with a mean of 4.511 and standard deviation of 0.745 , the functional staff in fibre-optic infrastructure departments in mobile telecommunication and internet service companies agreed that building code revision was necessary to allow for fibre-optic services in new buildings. They also agreed with a mean of 4.430 and standard deviation of 0.858 that introduction of utility corridors prevented repeated digging that interfered with other underground infrastructure. In addition, they agreed that more regulations should be put in place to check on implementation of fibre-optic infrastructure as shown by a mean of 4.290 and standard deviation of 0.876 .

Moreover, with a mean of 4.232 and standard deviation of 1.033, the functional staff agreed that significant delays in execution of fibre-optic infrastructure were because of delays in obtaining permits. Furthermore, they agreed that lack of coordination among multiple authorities in issuance of permits was the reason for significant delays in execution of fibre-optic infrastructure, as shown by a mean of 4.232 and standard deviation of 1.033. The functional staff agreed with a mean of 3.686 and standard deviation of 1.136, and regulations by the government on fibre-optic infrastructure were not fair and they need revision. They further agreed with a mean of 3.593 and standard deviation of 1.127, and there was adoption and customisation of global standards in implementation of fibre-optic infrastructure.

However, with a mean of 3.348 and standard deviation of 1.172, the functional staff were neutral on the statement indicating that the government of Kenya has implemented policy on fibre-optic infrastructure. In addition, the functional staff were neutral on the statement indicating that there was a uniform right of way policy for fibre-optic and other infrastructures, as shown by a mean of 2.953 and a standard deviation of 1.183. With a mean of 2.872 and standard deviation of 1.162, the functional staff were neutral on the statement indicating that the government implemented a dig once policy in conjunction with laying new roads and widening some.

\subsection{Descriptive analysis of government policy from visual analogue scale data}

The respondents were asked to rate the extent to which government policy is supportive to execution of fibre-optic infrastructure using a scale of $0-10$, where 0 represents least supportive and 10 represents most supportive. From the findings as shown in Table 5, 20.9\% rated the extent to which government policy is supportive to execution of fibre-optic infrastructure as 7, followed by $9.00(15.1 \%)$, 5.00 (14.0\%), 6.00 (11.6\%), 3.00 (5.8\%), 10.00 (3.5\%), 4.00 $(2.3 \%)$ and $2.00(1.2 \%)$. These findings demonstrated that government policy support to execution of fibre-optic infrastructure was rated as 7 and above on visual analogue scale by $65.12 \%$ of respondents. These findings imply that government policy is important and supportive in fibre-optic infrastructure and can result in effective, 
efficient and sustainable execution of fibre-optic infrastructure.

The key informants indicated that stakeholders were involved in policy matters regarding fibre-optic infrastructure through consultative meetings, as well as national and regional forums such as East African Communications Organisation (EACO). However, they added that there were no stand-alone regulations though there exist installation guidelines. The key informants also indicated that regulation of interconnection and fixed links encourage infrastructure sharing and further noted that specific government policies in fibre-optic infrastructure are contained in ICT Infrastructure Policy, ICT Policy and Communication Act, although the regulations were not adequate.

\subsection{Inferential statistical analysis of leadership skills, stakeholder management, government policy and execution of fibre-optic infrastructure}

Path analysis was conducted to ascertain intervening influence of government policy on the joint influence of leadership skills and stakeholder management on execution of fibre-optic infrastructure.

The null hypothesis stated that:

$\mathbf{H}_{\mathbf{0}}$ 1. There is no significant intervening influence of government policy on the joint influence of leadership skills and stakeholder management on execution of fibre-optic infrastructure.

The intervening variable led to the formation of three paths as shown in Figure 1. The first path (path a) was from independent variables to the intervening variable. The second path (path b) was from intervening variable to the dependent variable. The third path (path c), a direct influence path, was from independent variables to the dependent variable.
Where:

(a) Government policy (I) - intervening variable

(b) Execution of fibre-optic infrastructure (Y) - dependent variable

(c) Leadership skills $\left(\mathbf{X}_{1}\right)$ - independent variable

(d) Stakeholder management $\left(\mathbf{X}_{\mathbf{2}}\right)$ - independent variable

(e) Leadership skills-stakeholder management $\left(\mathbf{X}_{1}-\mathbf{X}_{2}\right)$ independent variables combined

$R^{2}$ of regression coefficient shows variation in the dependent variable that can be explained by the independent variable (Bryman 2012). The results given in Table 6 showed that $R^{2}$ for the relationship between leadership skills, stakeholder management and execution of fibre-optic infrastructure was 0.4889 . This indicated that leadership skills and stakeholder management combined explain $48.89 \%$ of the execution of fibre-optic infrastructure. The analysis of variance is used in regression analysis to assess whether the model is a good fit for data analysis (Bryman 2012). The $F$-calculated (162.60) was greater than $F$-critical (3.8415) and the significant level 0.05 was greater than the $p$-value $<0.001$. This indicated that the model may be used to predict the combined influence of leadership skills and stakeholder management on execution of fibre-optic infrastructure. The results indicated that leadership skills and stakeholder management combined had a significant influence on execution of

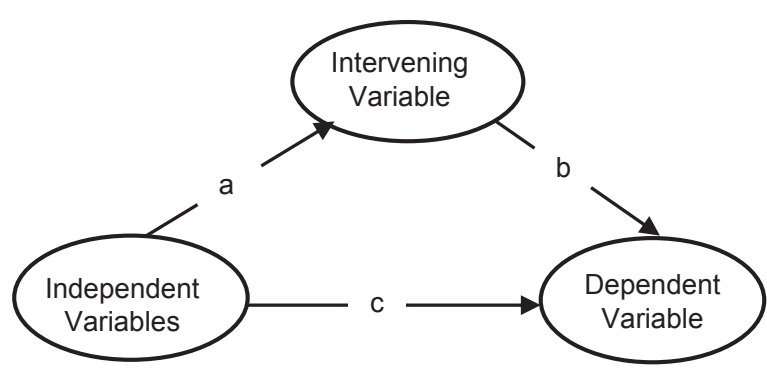

Fig. 1: Intervening model.

Tab. 6: Model with dependent variable regressed on independent variables (path c)

\begin{tabular}{|c|c|c|c|c|c|c|}
\hline Source & SS & df & MS & & Number of observations & 172 \\
\hline Model & 273.277533 & 1 & 273.277533 & & $F(1,170)$ & 162.6 \\
\hline Residual & 285.722467 & 170 & 1.6807204 & & Prob $>F$ & 0.000 \\
\hline \multirow[t]{3}{*}{ Total } & 559 & 171 & 3.26900585 & & $R^{2}$ & 0.4889 \\
\hline & & & & & Adjusted $R^{2}$ & 0.4859 \\
\hline & & & & & Root MSE & 1.2964 \\
\hline$Y$ & Coefficient & Standard error & $t$ & $p>[t]$ & {$[95 \% \mathrm{Cl}]$} & \\
\hline $\mathrm{X}_{1}-\mathrm{X}_{2}$ & 0.0505134 & 0.003961 & 12.75 & 0.000 & 0.0426935 & 0.058333 \\
\hline _cons & 4.787548 & 0.234566 & 20.41 & 0.000 & 4.32451 & 5.250585 \\
\hline
\end{tabular}


fibre-optic infrastructure since the regression coefficient was 0.05051 and the $p$-value $<0.001$ was less than the significance level 0.05 .

The $R^{2}$ for leadership skills, stakeholder management and government policy in Table 7 was 0.3429 . This indicated that leadership skills and stakeholder management combined explain $34.29 \%$ of government policy. The results also showed that the $F$-calculated (88.72) was greater than the $F$-critical (3.8415) and significant level of 0.05 was greater than the $p$-value $<0.001$. This suggested that the model was a good fit for the data and hence may be used to predict the joint influence of leadership skills and stakeholder management on government policy. The results also showed that leadership skills and stakeholder management combined had a significant influence on government policy as indicated by a regression coefficient of 0.4243 and a $p$-value $<0.001$.

The $R^{2}$ for the relationship among leadership skills, stakeholder management, government policy and execution of fibre-optic infrastructure was 0.6043 as shown in Table 8. This indicated that leadership skills and stakeholder management combined, and government policy explain $60.43 \%$ of execution of fibre-optic infrastructure. The results also showed that the $F$-calculated (129.02) was

Tab. 7: Model for the relationship between independent variables and intervening variable

\begin{tabular}{|c|c|c|c|c|c|c|}
\hline Source & SS & df & MS & & Number of observations & 172 \\
\hline Model & 192.889365 & 1 & 192.889365 & & $F(1,170)$ & 88.72 \\
\hline Residual & 369.622263 & 170 & 2.17424861 & & Prob $>F$ & 0.000 \\
\hline \multirow[t]{3}{*}{ Total } & 562.511628 & 171 & 3.28954168 & & $R^{2}$ & 0.3429 \\
\hline & & & & & Adjusted $R^{2}$ & 0.3390 \\
\hline & & & & & Root MSE & 1.4745 \\
\hline I & Coefficient & Standard error & $t$ & $p>[t]$ & {$[95 \% \mathrm{Cl}]$} & \\
\hline$X_{1}-X_{2}$ & 0.0424384 & 0.0045057 & 9.42 & 0.000 & 0.0335441 & 0.0513327 \\
\hline _cons & 4.628134 & 0.2667918 & 17.35 & 0.000 & 4.101483 & 5.154786 \\
\hline
\end{tabular}

Tab. 8: Model with dependent variable regressed on intervening variable and independent variables - paths $b$ and $c$

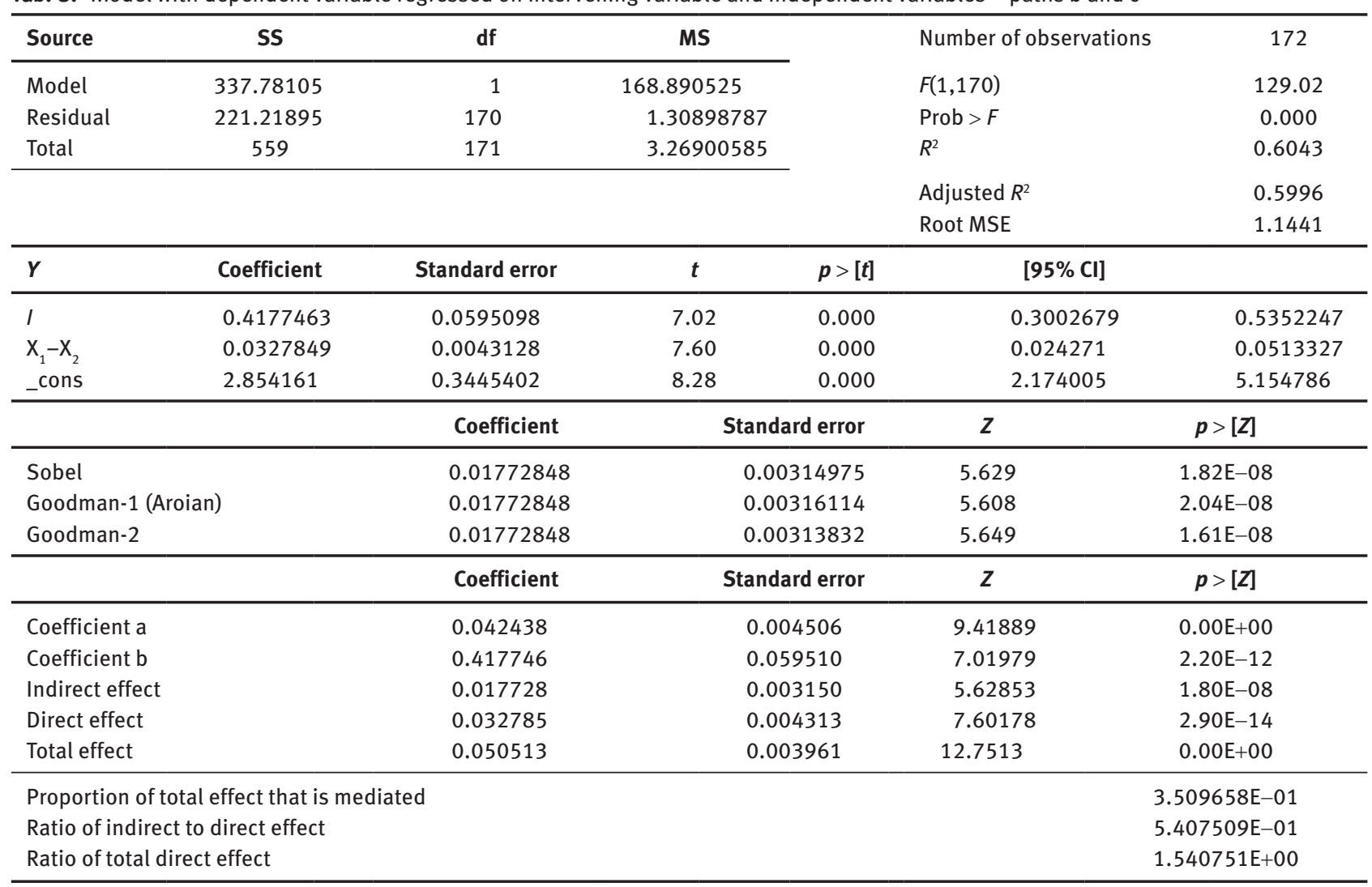


greater than the $F$-critical (2.9957) and the $p$-value $<0.001$ was less than the significance level 0.05 .

The results indicated that the model may be used to predict joint influence of leadership skills and stakeholder management, and government policy on execution of fibre-optic infrastructure. The results further showed that government policy had a significant influence on the execution of fibre-optic infrastructure as indicated by a regression coefficient of 0.4177 ( $p$-value $<0.001)$. In addition, leadership skills and stakeholder management had a significant influence on the execution of fibre-optic infrastructure as indicated by a regression coefficient of 0.03278 and $p$-value $<0.001$. In addition, the results showed that the total proportion of the mediated influence was $35.09 \%$. From these findings, the null hypothesis that there is no significant intervening influence of government policy on the joint influence of leadership skills and stakeholder management on execution of fibre-optic infrastructure was rejected, and the alternative hypothesis that there is significant intervening influence of government policy on the joint influence of leadership skills and stakeholder management on execution of fibre-optic infrastructure was accepted.

\section{Discussion}

In any type of a project, government policies assist to save time, avoid mistakes relating to management and improve steadiness in decision-making. The reports of Republic of Kenya (2016) indicated that a government has a huge influence on execution of any project. This is because it provides policies for improvement in project productivity, management and associated benefits to different stakeholders. In this regard, project scope planning, definition and verification must take into consideration regulatory policies in place for smooth execution of fibre-optic infrastructure.

This study established that there is a significant intervening influence of government policy on the joint influence of leadership skills and stakeholder management on execution of fibre-optic infrastructure. These findings are in line with those of Deloitte (2016) which showed that while project execution depends on various government policies such as building code, ICT policies and environmental policies, government policies also influence leadership and stakeholder management in different organisations. The findings also agree with the assertion by Moenga and Moronge (2016) who showed in their study that stakeholder participation, through wellplanned project scope under leadership of a competent project manager in fibre-optic infrastructure with strict adherence to government policies, helps to realise success in execution of fibre-optic projects.

Building code specifies and regulates the standards for design and construction of structures. It also specifies and regulates installations such as fibre-optic infrastructure. The study findings showed that revision of building code is required to allow for fibre-optic services in new buildings. They also showed that introduction of utility corridors prevented repeated digging that interfered with other underground infrastructure. These findings agree with the argument by Kraus and Quiroga (2016) who showed in their study that utilisation of utility strips, also known as utility corridors, plays a major role in preventing repeated digging that interferes with other underground infrastructure. In addition, it was demonstrated that more regulations should be put in place to check on how fibre-optic infrastructure is implemented. This is also in line with the findings of Moenga and Moronge (2016) that organisations should adopt a strategic plan for effective utilisation of fibre-optic infrastructure and that national ICT policy should articulate a strategic utilisation roadmap for the deployed fibre-optic infrastructure.

This study established that significant delays in execution of fibre-optic infrastructure were caused by delays in obtaining permits. Moreover, the study findings showed that lack of coordination among multiple authorities in issuance of permits was a reason for significant delays in execution of fibre-optic infrastructure. These findings agreed with those of Lampland and Mitchell (2014) who showed in their study that ambiguity around the process of obtaining permissions, delays caused by administrative paperwork and complex processes highlighted by authorities at the local government level negatively affect project success.

This study demonstrated that regulations by the government on fibre-optic infrastructure were perceived as unfair and needed revision. This is in agreement with findings of CIPESA (2016) that ICT policy involving ICT infrastructure in the country needed revision. In addition, Communication Authority of Kenya (2017) indicated that keeping in mind the need for advancing ubiquitous broadband, the Kenya National Telecom Policy needs revision with deeper focus on strategic direction, increased clarity around policy actions for implementation and a robust governance framework.

Furthermore, the findings revealed that there were adoption and customisation of global standards in the implementation of fibre-optic infrastructure. This is in line with the findings of Karakozova and Prokhorova 
(2016) that companies should adopt international standards in the implementation of fibre-optic infrastructure. However, the Government of Kenya had moderately implemented the policy on fibre-optic infrastructure. According to Republic of Kenya (2016), infrastructure-related policy that aimed to ensure affordable and widespread access to ICT services is required. This implied that there is inadequacy in the infrastructure-related policy to guide fibre-optic infrastructure.

However, Ameh and Ogunyemi (2015) revealed in their study that project scope planning, definition and verification must take into consideration the regulatory policies in place for smooth execution of fibre-optic infrastructure. In addition, there was no uniform right of way policy for fibre-optic infrastructure and other related infrastructure. While a uniform right of way is effective in preventing digging more than once, Kraus and Quiroga (2016) showed in their study that this was missing in most countries including Kenya. According to Jere and Biru (2015), destruction of fibre-optic network was as a result of regular fibre cuts by construction firms that do not adhere to procedures and municipality by-laws because of non-unified backbone infrastructure.

Moreover, the study findings showed that the Government of Kenya moderately implemented a dig once policy in conjunction with laying new roads and widening some. However, Strand (2015) showed that dig once policies minimise long-term cost of constructing communication facilities by capitalising on economies of scale. The application of dig once policy is by grouping of fibre and conduit construction with utility construction and other activities that interfere in the public right of way. It involves construction of spare conduit capacity where multiple service providers or entities may require infrastructure in future (Strand 2015). In addition, the assertion by CTC technology and energy (2017) showed that while fibre and conduit materials are relatively inexpensive, dig once construction is still costly.

\section{Conclusion and recommendations}

The objective of this study was to determine how government policy intervenes on the joint influence of leadership skills and stakeholder management on execution of fibre-optic infrastructure. This study adopted the pragmatism paradigm approach, with a cross-sectional survey design. A self-administered structured questionnaire was used to collect quantitative data while an interview guide was used to collect qualitative data. Census was used to select 187 respondents from a target population of 187 functional staff in fibre-optic infrastructure departments of two mobile telecommunication and four internet service companies in Nairobi County, Kenya. Quantitative data were analysed using descriptive and inferential statistics. Qualitative data were analysed using content analysis. The inferential statistics showed that the intervening influence of government policy on the joint influence of leadership skills and stakeholder management on execution of fibre-optic infrastructure is significant. It was therefore concluded that there is a significant intervening influence of government policy on the joint influence of leadership skills and stakeholder management on execution of fibre-optic infrastructure.

The study findings revealed that governments have no specific policies in fibre-optic infrastructure. This study therefore recommended that governments through ICT authority and other agencies should come up with policies to guide and regulate execution of fibre-optic infrastructure. The study findings also demonstrated that governments have not implemented a dig once policy in conjunction with laying new roads and widening some. This study, therefore, recommended development of right of way conduits that can be used by mobile telecommunication and internet service providing companies to install fibre-optic infrastructure instead of repeated ground digging that threaten to shorten life of streets, increasingly disrupt traffic, access to local businesses and interfere with other underground infrastructure.

Building code specifies and regulates standards for design and construction of structures. It also specifies and regulates installations such as fibre-optic infrastructure within buildings and other related structures. The study findings showed that building code needs revision to allow for fibre-optic services in new buildings. This study therefore recommended review of policies such as building code to allow for fibre-optic services in new buildings. It also established that significant delays in execution of fibre-optic infrastructure were because of delays in obtaining permits. Furthermore, the study findings revealed that lack of coordination among multiple authorities in issuance of permits was a reason for significant delays in execution of fibre-optic infrastructure. It is therefore recommended that governments should establish a centrally coordinated authority to facilitate time-bound issuance of permits, fees, charges and uniformity of policy.

This study was delimited to Nairobi County, which is the capital city of Kenya. However, fibre-optic infrastructure has also been implemented in other countries. Different countries experience different levels of success in the execution of fibre-optic infrastructure depending on other 
factors such as literacy level and level of development. It is therefore recommended that similar studies should be conducted in other countries across the world but target vendors and contractors engaged in supply of equipment and construction of fibre-optic infrastructure.

The importance of studying how government policy intervenes on the joint influence of leadership skills and stakeholder management on execution of fibre-optic infrastructure is further emphasised by the need of proactive approach in decision-making when it comes to the execution of fibre-optic infrastructure. Policies assist to save time, avoid mistakes related to management, improve steadiness in decision-making and focus on decisions made towards meeting business objectives. The governments should therefore provide an environment that is conducive for policy development incorporating views from private sector players in fibre-optic infrastructure. This study is an extended version of the paper on leadership skills, stakeholder management and execution of fibre-optic infrastructure published in Journal of Engineering, Projects, and Production Management (Akhwaba et al. 2020).

\section{References}

Akhwaba, J. K., Bowa, O., \& Keiyoro, P. (2020). Leadership skills, stakeholder management and execution of fibre optic infrastructure. Journal of Engineering, Projects, and Production management, 10(1), pp. 80-86.

Ameh, O. J., \& Ogunyemi, A. B. (2015). Challenges of scope definition for projects using conventional construction procurement method in Nigeria. Journal of Building Performance, 6(1), pp. 77-82.

Beardsley, S., Enriquez, L., Guvendi, M., \& Sandoval, S. (2011). Creating a fibre future: The regulatory challenge. The Global Information Technology Report 2010-2011 @ 2011 World Economic Forum. Available at http://reports.weforum.org/ $\mathrm{wp}$-content/pdf/gitr-2011/02-part-1/1.9-creating-a-fiber-future. pdf on 26 October, 2018.

Bryman, A. (2012). Social Research Methods, 4th edn. Oxford University Press, New York.

Collaboration on International ICT Policy in Eastern and Southern Africa. (2016). ICT in Governance in Kenya-Policies and Practice. CIPESA ICT Research Series No. 06/15, pp. 1-2. Available at https://www.cipesa.org/?wpfb_dl=200 on 2 November, 2018.

Communication Authority of Kenya. (2017). Quarterly Sector Statistics Report, Second Quarter of the Financial Year 2016/17, January - April 2017. Available at http://ca.go.ke/images/ downloads/STATISTICS/Sector\%20Statistics\%20Report\%20 Q1\%202016-2017.pdf on 3 November, 2018.

Crocker, S. (2012). National fibre program. Australian constructors Achievement award. Technical Paper 2012. NFP Commercial Manager, 18-20 Compark Circuit, Mulgrave Vic 3165. Leighton, pp. 1-9. Available at https://www.acaa.net.au/wp-content/ uploads/2015/05/NATIONAL-FIBRE-PROGRAM.pdf on 1 December, 2018.

CTC Technology and Energy. (2017). Technical Guide to Dig Once Policy. pp. 1-20. Available at https://www.ctcnet. us/wp-content/uploads/2017/05/CTC-White-PaperDig-Once-20170414.pdf on 1 December, 2018.

Deloitte. (2016). Broadband Infrastructure for transforming India. In: 9th International Conference on ICT and Digital Economy, India Telecom. pp. 1-68. Available at https:// www2.deloitte.com/content/dam/Deloitte/in/Documents/ technology-media-telecommunications/in-tmt-broadband-infrastructure-for-transforming-india-noexp.pdf on 26 September, 2018.

Dexter, F., \& Chestnut, D. H. (1995). Analysis of statistical tests to compare visual analogue scale measurements among groups. Anaesthesiology, 82(1), pp. 896-902.

Ernst \& Young. (2015). Global Telecommunications Study: Navigating the Road to 2020, Building a Better Working World. EYGM Limited. EYG No. EF0156 BMC Agency GA 0450_0293.

Ezeh, G. N., Ogbuehi, C. N., Eleke, N., \& Diala, U. H. (2013). Severity index analysis of the problems of optical fibre Communication in Nigeria: A case study of South Eastern Nigeria. Academic Research International, 4(1), pp. 431-438.

Gillwald, A., Moyo, M., \& Stork, C. (2012). What is happening in ICT in South Africa? Evidence for ICT Policy Action. Available at https://www.researchgate.net/publication/291345764_ Understanding_what_is_happening_in_ICT_in_South_Africa_ Evidence_for_ICT_Policy_Action on 27 October, 2018.

Huawei. (2016). Gig Band Network Development. White Paper. Huawei Industrial Base, Bantian Long Gang, Shenzhen, China, P. R. China. Available at www.huawei.com on 30 October, 2018.

Jere, T. N., \& Biru, T. (2015). Internet Development and Internet Governance in Africa, Internet Society. Galerie Jean-Malbuisson, Geneva Switzerland.

Karakozova, I., \& Prokhorova, Y. (2016). The factors affecting innovative activities and cost management. In: MATEC Web of Conferences, Vol. 73, p. 07015. EDP Sciences.

Kraus, E., \& Quiroga, C. (2016). Innovations in accommodation of longitudinal utility installations along controlled-access highways. Transportation Research Record: Journal of the Transportation Research Board, 2588, pp. 53-60.

Lampland, E., \& Mitchell, C. (2014). Santa Monica Net, An Incremental Approach to Building A Fibre Optic Network. Institute for Local Self Reliance. Available at www.ilsr.org on 11 November, 2018.

Massa, N. (2013). Fibre Optic Telecommunication, Fundamentals of Phonotonics. Springfield Technical Community College Springfield, University of Connecticut, Massachusetts.

Moenga, R. O., \& Moronge, M. (2016). Determinants of effective utilization of broadband infrastructure projects in Kenya: A case of national optic fibre backbone infrastructure project phase 1. Strategic Journal of Business \& Change Management, 3(2), pp. 484-515.

Morris, P. W. G. (1994). The Management of Projects: A New Model. Thomas Telford, London.

Qing, Y., \& Dekker, A. (2014). Stakeholder's management issues and leadership in project management: The way forward. International Journal of Education and Research, 2(2), pp. 1-8. 
Republic of Kenya. (2016). National Information and Technology (ICT) Policy. Ministry of Information and Communication Technology. Available at http://icta.go.ke/ pdf/National-ICT-Policy-20June2016.pdf on 11 November, 2018.

Sankara, A. (2014). Application of Standard Project Management Processes in Fibre Optic Cable Plant Project Management. Digi Bridge TelCo, pp. 1-10. Available at https://www.thefoa. org/tech/ref/1pstandards/Fiber\%200ptic\%20Project\%20 Management.pdf on 27 October, 2018.
Strand, R. (2015). Scandinavian stakeholder thinking, seminal offerings from the late Juha Näsi. Journal of Business Ethics, 127(1), pp. 89-105.

Torlak, M. (2013). Fibre Optic Communications Fibre Optic Communications. EE4367 Telecom. Switching \& Transmission, pp. 1-25. Available at https://personal.utdallas.edu/ torlak/courses/ ee4367/lectures/FIBEROPTICS.pdf on 1 December, 2018.

Vonglao, P. (2017). Application of fuzzy logic to improve the Likert scale to measure latent variables. Kasetsart Journal of Social Sciences, 38(3), pp. 337-334. 